\title{
8 On the question of decolonisation, gender and political communication
}

\author{
Sally Osei-Appiah
}

\section{Introduction}

In June 2019, the President of Ghana, Nana Addo Dankwah Akufo-Addo, came under much public criticism for his comments at a Women Deliver conference in Canada where he is reported to have said:

What I've seen in the two and a half years that I've been in office, that not enough movement is being made by the $52 \%$ of the Ghanaian population that are women to be able to be in a position to make decisions... we're not seeing enough dynamism and activism on the part of those we're seeking this new...I'm talking about dynamism where it mattered. Dynamism is not sitting around here and talking. I'm talking about electing people to parliament, controlling political parties because they're the instrument by which our societies make decisions. We're talking about decisions, not wishes and hopes.

Understandably, the most criticism came from Ghanaian women's groups and various civil society organisations, who felt that his disparaging comments disregarded their many years of political action resulting is endless frustrations and disappointments. In the aftermath, government spokespersons including women parliamentarians lined up to defend the president, but the damage had already been done. His comments at such a conference were not only ill-advised but also demonstrated his lack of appreciation of the structural barriers that impeded women in African societies. The idea that women's failure to gain leadership in politics is an individual responsibility rather than the result of historical, systemic barriers is not only disingenuous but also insidious. It presents a structural, societal problem as an individual issue, thereby removing attention from those who work to sustain that order, or who have the power to effect the necessary change. It also disregards the legacy of colonial rule which has contributed in the most part to the subjugated, lived experiences of many women in African societies. When women's issues are presented as micro rather than macro problems, it pushes them to the periphery of social consciousness which 
in turn diminishes their importance not just in politics but also in political communication. Decolonising political communication ensues that gender issues and concerns are revalourised in the subfield. It entails deconstructing our understandings of gender and women's lived experiences, including their struggles in society, to recognise the multiple intersecting layers of oppression they face largely as a consequence of colonial legacy, and how that has shaped their present status in society. As the co-editors note in the introduction, it is about raising consciousness around gender issues and contextualising them in political communication research. This will give space in the scholarship to the correct explication of the impediments that confront women in African societies and their impact thereof in relation to women's interaction with and communication about politics.

According to Tamale (2020:3), 'gender is a blind spot in mainstream decolonial scholarship on Africa' and the same is true for political communication research. In many countries in Africa, women form the majority. World Bank (2019) figures show that 33 out of 57 African countries have a majority female population. Yet, gender research in political communication research is very limited (Sandberg and Ohberg, 2017). There is a decidedly male normativity in political communication scholarship although it has been long established that women's experiences are not the same as men (Ross, 2017; Steeves and Awino, 2015). Women in African societies experience multiple, intersecting layers of oppression (Afisi, 2010; Ebulonuwa, 2009; Tamale, 2020), which are absent from the experiences of men. As Steeves and Awino (2015:86) assert, 'African women have experienced immense economic, political and ideological oppression'. The disproportionate impact on their lived experiences causes many disadvantages that are absent from the lives of men, and these also shape their political experiences.

Even within women's issues, contextualisation needs to occur to account for the differentiated experiences of women based on colonisation. The colonial history that women in the continent grapple with has so shaped their lives as to distinguish them from women in other Western and other contexts (Amadiume, 1987; Bosch, 2011; Ebunoluwa, 2009). Thus, in this decolonisation enterprise, gender also needs to be disentangled from race (Tamale, 2020). Much as women's experiences differ from men, so are African women's lived experiences dissimilar in many ways compared to their Western peers. In resisting Western hegemony in political communication, therefore, we must also resist a homogenisation of women's experiences.

Given the prevailing situation as described above, this chapter sets forth two key arguments. First, in order to decolonise political communication, it is necessary to decentre androcentrism in the scholarship by reclaiming an equal and complimentary not hierarchical space for women. Afisi (2010) rightly points out that in pre-colonial African societies, there was no gender inequality as each gender and their contribution to the community were regarded as important. Women occupied an equal and complimentary position to men in these traditional communities. St. Clair (1994:27) also 
notes that instead of patriarchy, there was a 'co-dependence and a balance that existed' among women and men prior to colonisation. Decolonising political communication therefore means bringing women back from the obscurity of the margins into the centre in a way that reflects their status in pre-colonial African societies. Second, decolonising political communication involves making explicit the contextual realities which distinguish African women's lived experiences from those in Western and other contexts. Centring the context within which African women are located ensues that the necessary nuance is achieved in the scholarship. In setting forth these two key arguments, the chapter focuses on Ghanaian and Nigerian women politicians, using their experiences to highlight some of the enduring effects of colonisation as well as gender norms which still shape how women politicians are perceived and evaluated, and which, in turn, affect their communication strategies. The chapter draws on 49 semi-structured interviews of women and men politicians, civil society experts and news workers in Ghana and Nigeria, all of which were conducted between October and November 2017.

\section{Decentring androcentrism in political communication}

Historically, politics has been regarded as a male preserve (AdeniyiOgunyankin, 2014; Sossou, 2013). This idea is so entrenched that women politicians are persistently framed as outsiders. It is no surprise, therefore, that male dominance in politics was a key theme that soon became apparent in the interviews. A female civil society expert in Nigeria notes:

When you think politics in Nigeria, you think male. (For) most people, if they think public office in Nigeria, they think male so even that orientation, that mindset is already a very big problem.

While the comment relates directly to Nigeria, Ghanaian interviewees observed the same as is likely the case in many other African countries. Male dominance in politics is also reflected in political communication research (see e.g. Agunbiade and Akiode, 2017; Ette, 2017; Maractho, 2018) where women are decentred and their representation is largely absent. However, as voters and politicians, the issues, concerns and struggles of women differ significantly from men. Culture ensues it while the media largely perpetuate it. To continue in this trend is to sustain patriarchal culture which has conditioned all aspects of life in African societies (Ndlovu and Mutale, 2013). Much evidence suggests that before colonial rule, African women enjoyed immense political, social and economic status (Chuku, 2018). This changed with the arrival of colonisation when the indigenous institutions which guaranteed women's authority and influence were replaced with a masculinised colonial administration that diminished women's power and social status (ibid; Adeniyi-Ogunyankin, 2014; Afisi, 2010). Callaway 
(1987:51), for instance, writes that the colonisers 'assumed African women generally to be in a dependent and subordinate position to men even in areas where women were noted for their independent trading activities and their political power'. In line with their Victorian values, they established a hierarchical gendered tradition characterised by gender roles in which women were assigned the subordinate and limiting private sphere of domesticity, while men occupied the more authoritative and politically engaging public sphere. Women were subsequently rendered less important and made invisible in the colonial rule that ensued (Adeniyi-Ogunyankin, 2014; Chuku, 2018; St. Clair, 1994).

The ideals of colonisation once established, endured as a legacy, firmly entrenched in the cultural gender expectations that define acceptable behaviour from women and men in most African societies. The result of such a colonial enterprise was the confinement of women to domestic life. At the time, the primary expectation of women was that of marriage, childbearing and caregiving, all of which were regarded as roles to be aspired for (Imafidon, 2013). If women were only expected to marry, give birth and take care of their households, then there was no need to invest in their education, train them professionally or build their leadership capabilities. Men, however, because they were viewed as natural leaders, were socialised and equipped to fulfil their role as decision-makers. They were seen as more politically competent and successful. Likewise, women who fulfilled their gender-defined roles as pertaining to the family were viewed as "responsible" while those seeking political office were viewed as challenging God's order, opening themselves up for stigmatisation, harassment and disapproval from family, friends and even other women (Adeniyi-Ogunyankin, 2014). As will be shown below, these gendered expectations associated with politics are also evident in the way women politicians are generally framed in media content. In the same way that the universalisation of Western ideology is no longer tenable, so it is unacceptable to continue with the androcentric focus in political communication scholarship when it only presents a limited understanding of political communication processes.

Another key institution that helps perpetuate women's subordinate status in society is culture. To illustrate its defining influence on women politicians, here is an explanation from one of the Ghanaian female politicians:

When we go to villages and have to pay homage to the chiefs, the chiefs will be sitting and as the candidate, I am probably there with the executives of that constituency so hierarchically I am higher. We walk into these chiefs' palace and they say to me "women don't go there". Traditionally, women shouldn't go there, or the men should go ahead of you to greet. You don't go ahead first. So, the men sit down. They are sitting in front and I am sitting at the back, and yet, I am going to address these chiefs. It is ridiculous. But this is culture or socialization or tradition. 
Apart from such traditional practices which ensure women's subordination to men, there are also proverbs which serve to rob women of their voice as explained by this male journalist:

I think Ghanaian female politicians are not as bold as you would expect of politicians seeking to lead the people. That has its own deep roots in the kind of values that we hold in a society like Ghana, the fact that (culturally, we say) "ok men are talking; you women must keep quiet". These are things that happen within a cultural setting, and they go a long way either directly or indirectly to influence how female politicians carry themselves.

Traditionally, women are expected to defer to men as husbands and leaders of the community. There is a popular Akan adage, for example, that states that women must only be seen and not heard. Yet, to be successful in politics, politicians are expected to not only be vocal but also articulate in communicating their views and policies. Thus, for women politicians, the deliberate cultural effort to deprive women of their power of expression is especially damaging as it goes contrary to the very nature of politics. These contradictions therefore present quite a dilemma for women politicians, particularly as the media grows increasingly influential in politics (Strömbäck and Esser, 2014). To conform to gender expectations is to set themselves up for obscurity and a potential end to their political careers. To resist it risks setting themselves up for public abuse. These are the sorts of challenges which women politicians continually tackle but which are absent for male politicians. They highlight the gendered disparities apparent in African cultures, which subsequently also affects how women politicians communicate. Challenges such as these do not just relate to voice but also to legitimacy. Being allowed to speak confers legitimacy, authority and importance (O'Neill et al., 2016; Wagner et al., 2017). The fact that women politicians are denied these culturally is evidence of the inequalities that persist, which also must be reflected in political communication research. Given these gendered differences, women can no longer be ignored as this female civil society expert in Ghana asserts:

Women cannot be disregarded. First of all, they present a different perspective. They have different needs; they have different concerns and those concerns and needs and cannot be represented by people who don't have or experience them.

As noted, women bring different perspectives that can only enrich political communication research. A deliberate effort to centre women's issues in the research agenda will not only facilitate better and more comprehensive theorising in the subfield, but also open new areas of enquiry to enable better understanding of phenomenon that confront scholars in their research. 


\section{Contextualising gender in political communication research}

Salgado (2019) makes a strong case on the need to contextualise research in political communication in order to avoid what Sartori (1970) calls "conceptual stretching". One area that can benefit much from contextualisation is research on women. In many ways, African women's experiences differ from Western women. For one thing, Western women do not have to deal with the taxing baggage of colonisation. Further, the concept of womanhood in African societies is inscribed in cultural values which espouse a high level of awareness of and responsibility to family and community as well as adherence to high social etiquette, all of which signify female beauty (Chuku, 2018; Imafidon, 2013). This contrasts with Western feminist ideals of independence (Imafidon, 2013). Steady (2007:154) for instance notes that 'the study of women and gender in Africa in the $21^{\text {st }}$ century cannot escape the realities of post-colonial hegemonic domination of Africa by Europe and North America'. This suggests that the way womanhood is conceptualised in Africa carries cultural resonances that are absent in expectations of Western women. It is important to acknowledge this in political communication research which focuses on gender. Tamale (2018:45) also argues that 'the oppression of African women intersects with other forms of structural oppression (based on race, ethnicity, class, religion, disability, sexual orientation, etc.) to compound their injustices'. Women in African societies do not only have to tackle gender biases but also resist the homogenisation of their lived experiences. This implies that even within the category gender, distinction needs to be made between various other layers of discrimination such as race because gender, after all, is both a historical and cultural phenomenon (Oyewumi, 2005). The way African women - as voters and as politicians - experience, relate to and communicate politics are coloured with the residue of the cultural infrastructures established during colonial rule. In contextualising gender research in political communication, we can begin to unpack the various context-dependent factors which culminate in shaping African women's experiences in quite distinct ways. In particular, we can consider the effects of incentive-driven coverage by African media and social media on women politicians' communication.

As a constitutive part of the triad of political communication (besides political actors and citizens), the media play a crucial role in contemporary politics. Increasingly, the media have become 'a dominant space in politics today' (Dahlgren, 2000:313), leading to a highly mediatised political terrain (O’Neill et al., 2016). It is safe to say that in many countries, including those in Africa, the media are the "primary source of symbolic material out of which people construct their understanding and evaluation of political actors, conditions and events' (Dan and Iorgoveanu, 2013:1028). Yet, as with culture, the media are not neutral but very gendered in their coverage of political news and actors (Anderson et al., 2011; Ette, 2017; O'Neill et al., 2016; Ross, 2017). There is overwhelming evidence that points to biased media 
coverage which favours male politicians in terms of giving them voice, more space, greater range of topics to speak on and an essentially issue-based coverage, while female politicians have to contend with erosion of their presence and voice, marginalisation, infantilisation as well as trivialisation of their political contributions(Ette, 2017; Ibroscheva and Raicheva-Stover, 2009; Osei-Appiah, 2019; Ross, 2017). For example, Katembo (2005) shows that during the 2004 South African general election, only 26 women politicians were used as news sources in the Sunday Times compared to 313 male politicians. Anderson et al. (2011) also reveal that coverage of Ellen Johnson Sirleaf in both local and international newspapers highlighted her physical appearance, maternal and marital status while her male political opponent, George Weah, was spared the sexist coverage. These examples highlight the media's complicity in perpetuating both the erasure and trivialisation of women's political contribution which also affects how they are perceived and evaluated by voters. In so doing, the media serve to sustain the colonial enterprise of male dominance in politics as such practices not only contribute to less favourable evaluations of female candidates but also discourage women politicians from engaging with the media (Ette, 2017; Osei-appiah, 2019; Ross, 2017).

One of the ways biased coverage manifests itself is through incentivedriven reporting whereby event organisers including political actors pay media houses to cover their events. Payment can be in the form of cash or in kind. The practice is quite endemic among media organisations in most of Africa (Amankwah et al., 2017; Osei-Appiah, 2019; Sampaio-Dias, 2019; Skjerdal, 2018). The challenge with incentive-driven coverage is that it creates a media culture that undermines the ideals of journalism in that it facilitates biased reporting while constraining diversity in media content (Sampaio-Dias, 2019). In particular, it is exclusionary as it prevents many women politicians from being seen and heard in the media space because they are unable to pay for coverage (Osei-Appiah, 2019). In the interviews, there was unanimous consensus among women politicians that their biggest challenge is finance. Yet, political advertising was one of the most expensive. There were many who said they were either absent or had very limited media visibility due to their inability to pay. Here is what a Nigerian female politician had to say:

For traditional media, you have to be either invited or pay. I had a few invitations like that, but I was not able to advertise because what happens in Nigeria is that for the media, the jackpot is their advertorial prices during elections. They say this is the time they can make a lot of money so that $30-40$ seconds on television will cost you like almost a millionaire naira.

Limited media coverage implies few opportunities to make themselves visible as candidates, to communicate their policies and issue positions, and to 
contribute to political debates. This ultimately affects the quality of political information presented to citizens as it only reflects a partial view of the political reality in that context (Osei-Appiah, 2019). Despite its pervasiveness in African journalism, research has shown that incentive-driven coverage is a phenomenon that is not common in Western contexts (Mabweazara, 2018). This means one less commonality between women in Africa and those in the West.

Another key context-dependent factor which distinguishes African women's experiences from those in the West is social media and the extent to which they are embedded in political communication strategies in the continent. Some scholars have heralded social media for their equalising ability to increase access for both elite and marginalised groups (Boulianne, 2015; Diamond, 2010). Such optimism, however, does not take into account prevailing realities in non-Western contexts such as in Africa where, among others, internet costs are not only prohibitively expensive but also quite unstable in many areas (Dwyer and Molony, 2018). In fact, sub-Saharan Africa has one of the lowest rates of internet penetration in the world, showing a penetration rate of $32 \%$ which is well below the world average of $42 \%$ (Dzisah, 2018). It must be noted, however, that due to the rapid expansion of mobile telephony and the rate of internet penetration in the continent, future projections are very optimistic. Nonetheless, we also need to acknowledge that social media use is not the norm in Africa (Nyabola, 2018) as it is in the West. In fact, there are gendered disparities in social media access which Dwyer and Molony (2018:3) argue 'often overlap with broader issues of socio-economic gender inequalities'. Difficulties with erratic power supply and high levels of illiteracy in many parts of Africa also influence politicians' perceptions about social media's value to their political goals. For example, some women politicians believed that social media was more for educated people than illiterates which suggested that those who represented rural communities found less need for their use. The following quote by one of the Ghanaian women politicians illustrates this point:

In the village, you don't always have Internet so if you're in a rural constituency, social media may work with the students but they're still a minority...those thousands of women who, as a woman, are your natural supporters, they will support you, but they will not check social media. You have to use the simplest form of media you can use to get to them.

Others also noted difficulties with maintaining internet connectivity during campaign road trips as well as lack of technical knowhow regarding how the platforms operate. Another Ghanaian women politician described her experience:

I'm learning it as well. It's a new thing for me and I need to just learn it. I'm fast now. I don't even know how to get to Twitter but I had a young lady here and I'd tell her what I want and she would do it on Twitter. 
It must be noted, however, that while these views were quite dominant in the interviews, there were also women politicians who used social media extensively in their campaigns. The divergent views represented in the interviews suggested that there were mediating factors which affected women politicians' use motives. These generally related to the demographics of constituency members, age and technical literacy of the politician as well as political function. Women politicians who did not know how social media sites operate, who contested at the local level or whose constituencies were located in rural areas generally used social media less if at all, while those representing urban areas, contesting for national positions or having greater financial freedom, were more likely to regularly use social media. Some of these factors, particularly those relating to connectivity challenges, high cost of data and illiteracy, are issues which demonstrate differences in contexts for African women and those in the West.

\section{Conclusion}

In this chapter, I have proposed two ways that political communication can be decolonised in relation to gender. I have argued for a refocus in political communication research which entails decentring its androcentric predominance and recentring gender-sensitive research in ways that accord complimentary importance to women's issues. Just as it is necessary to destabilise the Western dominance in the subfield, so it is that our present appetite as African scholars should make it equally intolerable to maintain the current male dominance in the scholarship. This is not to suggest a "take over" of women's issues in the subfield. It is simply to point out that not doing this risks producing knowledge that only provides a limited view of the range of topics, issues and concerns in the political realities that engage us as scholars of political communication. Inclusion and diversity have recently become trendy terms which can be usefully appropriated in this context. Recentring gender in political communication will ensure greater diversity in the scope of research while also guaranteeing fair representation.

Beyond recentring gender, I have also argued for contextualisation in gender research to allow for greater nuance in research findings. The impact of context in shaping political processes and practices needs no emphasis as it is quite evident (Salgado, 2019). Therefore, it is necessary that we resist the homogenisation of women's experiences in the subfield by emphasising context in gender research. This will eliminate the risk of overlooking important causative elements which shape the phenomenon we study while also facilitating a better understanding of the complexities that context often presents in empirical research. Decolonising political communication should therefore entail an explicit reference to the influence of context within the boundaries of gender-sensitive research. Following these two proposals as outlined above will inevitably lead to richer, more equitable and more diverse scholarship which will ultimately facilitate better theorising in the subfield. 


\section{References}

Adeniyi-Ogunyankin, G. 2014. "Spare Tires," "Second Fiddle," and "Prostitutes"? Nokoko. 4, p. 11.

Afisi, O.T. 2010. Power and Womanhood in Africa: An Introductory Evaluation. The Journal of Pan-African Studies. 3(6), pp. 229-238.

Agunbiade, T. and Akiode, O. 2017 Gender and Political Communication in Africa. In: A. Olukotun and S. Omotoso, eds. Political Communication in Africa. Springer, Cham. https://doi.org/10.1007/978-3-319-48631-4_10

Akufo-Addo, N.A. 2019. Speech at Women Deliver Conference. Accessed 12 December 2020. Retrieved from Joy News - President Nana Akufo-Addo at the much talked about Women Deliver Conference 2019 in Vancouver, Canada \#JoyNews - Bing video

Amadiume, I. 1987. Male Daughters, Female Husbands: Gender and Sex in an African Society. Basingstoke: Palgrave Macmillan.

Amankwah, A.S., Ako-Gyima, E. and Quansah, J. 2017. The 'Brown Envelop' and Media Practice in Ghana: A Socio-cultural Perspective. Journal of Communication, Media and Society. 4(1), pp. 43-61.

Anderson, J.A., Diabah, G. and Mensah, P.A. 2011. Powerful Women in Powerless Language: Media Misrepresentation of African Women in Politics (the Case of Liberia). Journal of Pragmatics. 43(10), pp. 2509-2518.

Bosch, T. 2011. African Feminist Media Studies: A View from the Global South. Feminist Media Studies. 11(01), pp. 27-33.

Boulianne, S. 2015. Social Media Use and Participation: A Meta-Analysis of Current Research. Information, Communication and Society. 18(5), pp. 524-538.

Callaway, H. 1987. Gender, Culture and Empire: European Women in Colonial Nigeria. London: Palgrave Macmillan.

Chuku, G. 2018. Colonialism and African Womanhood. In S. Martin and F. Toyin, eds. The Palgrave Handbook of African Colonial and Postcolonial History (pp. 171-211). New York: Palgrave Macmillan.

Dahlgren, P. 2000. Media, Citizenship and Civic Culture. In: J. Curran and M. Gurevitch, eds. Mass Media and Society (pp. 310-328). London: Edward Arnold.

Dan, V. and Iorgoveanu, A. 2013. Still on the Beaten Path: How Gender Impacted the Coverage of Male and Female Romanian Candidates for European Office. The International Journal of Press/Politics. 18 (2), pp. 208-233.

Diamond, L. 2010. Liberation Technology. Journal of Democracy. 21(3), pp. 69-83.

Dwyer, M. and Molony, T. 2019. Social Media and Politics in Africa. London: Zed Books.

Dzisah, W.S. 2018. Social Media and Elections in Ghana: Enhancing Democratic Participation. African Journalism Studies. 39(1), pp. 27-47.

Ebunoluwa, S.M. 2009. Feminism: The Quest for an African Variant. The Journal of Pan African Studies. 3(1), pp. 227-234.

Ette, M. 2017. Where are the Women? Evaluating Visibility of Nigerian Female Politicians in News Media Space. Gender, Place \& Culture. 24(10), pp. 1480-1497.

Ibroscheva, E. and Raicheva-Stover, M. 2009. Engendering Transition: Portrayals of Female Politicians in the Bulgarian Press. The Howard Journal of Communications. 20(2), pp. 111-128.

Imafidon, E. 2013. 'Miss Independent': Gender and Independence on the African Continent. Inkanyiso: Journal of Humanities and Social Sciences. 5(1), pp. 21-30. 
Katembo, T.K. 2005. The Representation of South African Women Politicians in the Sunday Times During the 2004 Presidential and General Elections. Unpublished MA dissertation. Accessed 10 December 2020. Retrieved from: https:// core.ac.uk/download/pdf/49241569.pdf

Mabweazara, H. 2018. Reinvigorating 'Age-Old Questions': African Journalism Cultures and the Falacy of Global Normative In: H. Mabweazara, ed. Newsmaking Cultures in Africa-Normative Trends in the Dynamics of Socio-Political \& Economic Struggles (pp. 1-29). Basingstoke: Palgrave Macmillan.

Maractho, E.C. 2018. Determinants of Participation in Political Communication in Uganda's Broadcast Media: Implications for Women. In B. Mutsvairo and B. Karam, eds. Perspectives on Political Communication in Africa (pp. 79-94). Cham: Palgrave Macmillan.

Nyabola, N. 2018. Digital Democracy, Analogue Politics: How the Internet is Transforming Kenya. London: Zed books.

Ndlovu, S. and Mutale, S.B. 2013. Emerging Trends in Women's Participation in Politics in Africa. American International Journal of Contemporary Research. 3, pp. 72-79.

O’Neill, D., Savigny, H. and Cann, V. 2016. Women Politicians in the UK Press: Not Seen and Not Heard? Feminist Media Studies. 16(2), pp. 293-307.

Osei-Appiah, S. 2019. News Media Logic and Democracy: Strange Bedfellows in Political News-Making Practices of Private Radio Stations in Ghana. African Journalism Studies. 40(3), pp. 57-72.

Oyewumi, O. 2005. Visualizing the Body: Western Theories and African Subjects. In African Gender Studies A Reader (pp. 3-21). New York: Palgrave Macmillan.

Ross, K. 2017. Gender, Politics, News: A Game of Three Sides. Oxford: Wiley-Blackwell.

Salgado, S. 2019. Never Say Never ... Or the Value of Context in Political Communication Research. Political Communication. 36(4), pp. 671-675.

Sampaio-Dias, S. 2019. Per Diem Payments as a Form of Censorship and Control: The Case of Guinea-Bissau's Journalism. Journalism Studies. 20(16), pp. 2349-2365.

Sandberg, L.A.C. and Öhberg, P. 2017. The Role of Gender in Online Campaigning: Swedish Candidates' Motives and Use of Social Media During the European Election 2014. Journal of Information Technology \& Politics. 14(4), pp. 314-333.

Sartori, G. 1970. Concept Misformation in Comparative Politics. The American Political Science Review. 64(4), pp. 1033-1053. doi:10.2307/1958356

Skjerdal, T. 2018. Brown Envelope Journalism: The Contradiction Between Ethical Mindset and Unethical Practice In: H.M. Mabweazara, ed. Newsmaking Cultures in Africa - Normative Trends in the Dynamics of Socio-Political \& Economic Struggles (pp. 163-185). Basingstoke: Palgrave Macmillan.

Sossou, M.-A. 2011. We Do Not Enjoy Equal Political Rights. SAGE Open. 1(1). doi:10.1177/2158244011410715.

St. Clair, William. 1994. Imperialism and Traditional African Culture. Cambridge: Cambridge University Press.

Steady, F. 2007. African Women: Re-Centering the Issues for the 21st century In: A. Mazama, ed. Africa in the 21st Century: Toward a New Future (pp. 133-154). London: Routledge.

Steeves, H.L. and Awino, I. 2015. Gender divides and African journalism practice. African Journalism Studies. 36(1), pp. 84-92. 
Strömbäck, J. and Esser, F. 2014. Mediatization of Politics: Towards a Theoretical framework In: F. Esser and J. Strömbäck, eds. Mediatization of Politics Understanding the Transformation of Western Democracies (pp. 3-28). London: Palgrave Macmillan.

Tamale, S. 2020. Decolonization and Afro-Feminism. Ottawa: Daraja Press.

Wagner, A., Trimble, L., Sampert, S. and Gerrits, B. 2017. Gender, Competitiveness, and Candidate Visibility in Newspaper Coverage of Canadian Party Leadership Contests. The International Journal of Press/Politics. 22(4), pp. 471-489. 